\title{
BMJ Open Individual and environmental factors associated with death of cyclists involved in road crashes in Spain: a cohort study
}

\author{
Daniel Molina-Soberanes, ${ }^{1,2}$ Virginia Martínez-Ruiz, ${ }^{1,3,4}$ Pablo Lardelli-Claret, ${ }^{1,3,4}$ \\ José Pulido-Manzanero, 3,5,6 Luis Miguel Martín-delosReyes, ${ }^{1,2}$ \\ Elena Moreno-Roldán, ${ }^{1,3,4}$ Eladio Jiménez-Mejías ${ }^{1,3,4}$
}

To cite: Molina-Soberanes D, Martínez-Ruiz V, LardelliClaret $P$, et al. Individual and environmental factors associated with death of cyclists involved in road crashes in Spain: a cohort study. BMJ Open 2019;9:e028039. doi:10.1136/ bmjopen-2018-028039

- Prepublication history and additional material for this paper are available online. To view these files, please visit the journal online (http://dx.doi. org/10.1136/bmjopen-2018028039).

Received 19 November 2018 Revised 16 July 2019 Accepted 31 July 2019

Check for updates

(C) Author(s) (or their employer(s)) 2019. Re-use permitted under CC BY-NC. No commercial re-use. See rights and permissions. Published by BMJ.

For numbered affiliations see end of article.

Correspondence to Dr Virginia Martínez-Ruiz; virmruiz@ugr.es

\section{ABSTRACT}

Objective To quantify the magnitude of associations between cyclist fatalities and both cyclist and environment related characteristics in Spain during the first 24 hours after a crash.

Design Cohort study.

Setting Spain.

Participants 65977 cyclists injured in road crashes recorded between 1993 and 2013 in the Spanish Register of Road Crashes with Victims.

Main outcome Death within the first 24 hours after the crash.

Methods A multiple imputation procedure was used to mitigate the effect of missing values. Differences between regions were assumed and managed with multilevel analysis at the cyclist and province levels. Incidence density ratios (IDR) with $95 \% \mathrm{Cl}$ were calculated with a multivariate Poisson model.

Results Non-use of a helmet was directly associated with death (IDR 1.43, 95\% Cl 1.25 to 1.64). Among other cyclist characteristics, age after the third decade of life was also directly associated with death, especially in older cyclists ('over 74 ' category, IDR $4.61,95 \% \mathrm{Cl} 3.49$ to 6.08 ). The association with death did not differ between work-related cycling and other reasons for cycling.

There was an inverse association with death for crashes in urban areas and on community roads. Any adverse meteorological condition also showed a direct association with death, whereas altered road surfaces showed an inverse association. Crashes during nighttime were directly associated with death, with a peak between 3:00 and 5:59 am (IDR $1.58,95 \% \mathrm{Cl} 1.03$ to 2.41$)$.

Conclusions We found strong direct and inverse associations between several cyclist and environment related variables and death. These variables should be considered in efforts to prioritise public health measures aimed at reducing the number of cycling-related fatalities.

\section{INTRODUCTION}

Cycling is considered a healthy alternative to private cars because it helps increase physical activity and reduce carbon emissions. ${ }^{1}$ But it can also be harmful: there are about 5.5 times more traffic deaths per kilometre travelled
Strengths and limitations of this study

- We used a nationwide database with information on 65977 cyclists.

- The database compiles abundant information on the characteristics of the people involved, their vehicles and the environment.

- Because the database is a police-based registry, it can be assumed that less serious crashes are underrepresented.

- Because of missing data, information biases cannot be ruled out despite the multiple imputation procedure used.

by bicycle than by car. $^{2}$ In fact, cyclists along with pedestrians are the most vulnerable road users because of their lack of protection and comparatively greater likelihood of suffering severe injuries or dying after a crash. ${ }^{3}$ These outcomes can be caused mainly by factors related to the cyclist (as in single-vehicle crashes) or related to other road users (as in collisions with other vehicles), or even by environment-related factors. Understanding the factors involved in cyclist injuries and deaths is necessary in order to design and promote better public policies worldwide to encourage safe cycling. The current transition in commuting patterns in Spain merits attention, because the number of people who use bicycles daily or almost daily has nearly doubled since the mid-2000s. ${ }^{4}$ Public policies in this country promote cycling not only as a leisure activity, but as a regular mode of transport. Although the annual number of cyclist deaths decreased from 75 to 58 between 2006 and $2015,{ }^{5}$ this tendency is reverting, and interventions aimed at making cycling a safer activity are needed. ${ }^{6}$

Many previous studies have identified individual and/or environmental factors 
associated with injury severity or fatalities among cyclists. ${ }^{7-18}$ However, there is no consensus regarding the magnitude or even the direction of some observed associations. Death is sometimes considered the most severe injury category along with other serious injuries, rather than as a specific category itself. ${ }^{7-9} 1116$ Because death of one or more cyclists after a crash is uncommon, some studies found no statistically significant associations between this outcome and a number of variables, ${ }^{7}$ and multivariate analysis was not possible in some studies because of the small numbers involved. ${ }^{16}$ In studies that reported significant associations, the findings may still be debatable: recent meta-analyses have consistently shown an inverse association between helmet use and head injury severity, although these studies focused mainly on non-fatal injuries. ${ }^{19} 20$ Olivier and Creighton ${ }^{19}$ found only two studies that reported effect sizes for fatalities, and Høye ${ }^{20}$ was obliged to merge fatalities with serious injuries in a single category for most of her analyses.

Regarding age and gender differences, the biological effect of ageing is a plausible cause for the association between cyclist involvement in a road crash and greater injury severity, ${ }^{8-12} 141618$ but the relationship between age and death in some age groups (eg, children or adolescents) awaits clarification. ${ }^{9} 141618$ Both males ${ }^{131618}$ and females ${ }^{12}$ have been reported to be at increased risk of more severe injuries. Physical and behavioural aspects related to gender have been argued to explain differences in injury severity, ${ }^{21-23}$ but there is no consensus.

Although alcohol consumption is known to be associated with risky behaviour while cycling, ${ }^{24}{ }^{25}$ studies focusing on the association between this factor and injury severity or fatality are inconclusive. ${ }^{10} 12141718$ The commission of infractions is reportedly associated with injury severity or death, but only in bicycle collisions with a motor vehicle, not on other types of crashes. ${ }^{10}$

Environmental factors can also play a major role as independent variables in fatal outcomes. Traffic lane characteristics, for example, intersections as opposed to open roadways, are usually related to an increased risk of collision but not necessarily with more severe injuries ${ }^{11} 1214$ except in unsignalised intersections. ${ }^{9}$ Road surface and adverse weather circumstances appear to be related to the likelihood of crashes, but their association with injury severity or death also requires clarification, given that previous studies have found both a direct association with injuries or death ${ }^{910} 14$ and no association. ${ }^{71-13}$ Time of day is related to conspicuity, and has been linked to crash rates. However, the association found for injury severity has not shown a clear direction: a direct association with severity has been reported during daytime ${ }^{71014}$ and during nighttime, ${ }^{911}$ with some analyses finding no association at all. ${ }^{1213}$

It seems obvious that cycling speed would be related to death after a crash. Although the speed at the time of the crash can be estimated with ad hoc studies using accident reconstruction techniques, ${ }^{26}$ proxy variables such as speed limit at the site of the crash, ${ }^{1011} 1314$ or the area of the crash $^{71114}$ have been widely used. In fact, speed may be the main reason for the greater severity of cyclists' injuries in crashes involving a motor vehicle compared with single crashes, as reported in previous studies. ${ }^{2} 1316$

Previous research in Spain has focused on impacts on cyclists' health, ${ }^{27} 28$ their behaviour and other correlates with crash involvement, ${ }^{21} 222930$ and the causal chain of events related to death after a crash. ${ }^{31}$ However, to our knowledge, there have been no attempts to analyse personal and environmental characteristics and their relationship with the risk of death.

To help fill the gaps in our current knowledge, we designed a large nationwide study to quantify the magnitude of the associations between cyclist and environment related characteristics and the likelihood of cyclist fatality within the first 24 hours post crash in Spain between 1993 and 2013.

\section{METHODS}

\section{Data source and study population}

We analysed the cohort comprising all 65977 cyclists involved in road crashes recorded in the Spanish National Registry of Road Crashes with Victims between 1993 and 2013 once the crashes in the autonomous cities of Ceuta and Melilla were excluded because of their specific characteristics and low mortality: both cities are located in northern Africa, and all road crashes involving cyclists occurred in urban areas.

The aforementioned registry is a nationwide electronic database maintained by the Spanish General Directorate of Traffic. It has high security standards to protect anonymity, and was developed to support the design and evaluation of public policies concerning road safety. Researchers can use these data on specific request, after a motivation letter is accepted by the Directorate authorities. This database contains information from the Statistical Questionnaire of the Accident documents submitted for every crash resulting in injury or death and involving at least one moving vehicle in areas subject to traffic laws. Information in the registry includes the characteristics of the persons involved (eg, age and sex), their vehicles (eg, type and condition) and the environment (eg, type of crash, geographic coordinates and road characteristics). It does not include information that may lead to personal identification. Victims are categorised as injured if they are seen by a healthcare service, or as dead if they die at the crash scene or within the first 30 days. This questionnaire is completed by national police agents at the crash scene, and filed within the first 24 hours for crashes that result in death or severe injury (needing hospitalisation), or within the next 10 days after the crash. All data must be submitted within the first 30 days post event, including follow-up information from healthcare services. Amendments to the infrastructure data recorded at the crash scene can be made within the next 30 days by the appropriate authorities. ${ }^{32}$ 


\section{Patient and public involvement}

This study relies on data collected by the Spanish General Directorate of Traffic; no patients or participants interacted with the study authors.

\section{Variables}

We collected information about a subset of variables which, according to previous studies and based on univariate analysis, may be associated directly or indirectly with injury severity. Our dependent variable was death within the first 24 hours after the crash, and the independent variables were cyclist related (age, sex, helmet use, psychophysical circumstances, nationality, commission of infraction and reason for cycling) and crash or environment related (type of crash, traffic lane characteristics, area, meteorological conditions, road surface, time of day, year and province). Original categories and dichotomised categories (see Statistical analysis section) can be viewed in the frequency distribution tables (tables 1 and 2).

\section{Statistical analysis}

Univariate analysis was first done for each variable included as an independent variable and for death as the dependent variable. Then we built a Poisson regression model (a generalised linear model which uses log (rate) as the link function). Spain is divided into 50 provinces which differ markedly regarding cycling density, cycler-friendly environment, socioeconomic conditions and healthcare facilities, among other important factors potentially related with cyclists' risk of death. Therefore, we first tested the hypothesis that the province level would explain a significant part on the total variance in the outcome variable (cyclist fatalities). For this purpose, we constructed both unilevel (online supplementary appendices 1 and 2) and multilevel empty models (including cyclist-level and province-level), and compared the variances explained by each. Significant differences $(p<0.001$ for the likelihood ratio test) between the two models were obtained, thus confirming our hypothesis. This led us to choose a multilevel multivariate model for the main results.

More than $25 \%$ of the data were missing for some variables (eg, helmet use) (see tables 1 and 2 for details). The overall amount of these missing values may be explained by missing at random (MAR) and missing not at random (MNAR) mechanisms. Although we cannot compensate for MNAR values, we can control MAR values through a multiple imputation procedure. Therefore, we initially assumed that some missing values might be explained by the combination of the values observed for some of the remaining variables in the database. To test this assumption, for each variable with missing values, we constructed a multivariate regression model with the existence or not of missing values as the dependent variable, and the observed values for the remaining variables as independent terms. In all cases, we observed parameters of association significantly away from the null. These results supported our initial hypothesis and led us to build 50 files in which missing data were represented as stabilised variances estimated from different variables, according to the chained equations method described by van Buuren ${ }^{33}$ and implemented with the 'ice' command in Stata. ${ }^{34}$ This is a community-contributed Stata command focused on simplifying the imputation of categorical variables. However, this procedure was unable to provide missing values for many categorical variables with more than two strata when the frequency of responses in different categories was low, and we thus opted to dichotomise these variables. The dichotomisation process considered theoretical similarities between original categories (eg, any adverse weather circumstances such as rain, snow and hail were grouped in the category 'any adverse circumstances') and tried to keep the most important category for analysis unaltered (eg, intersections). Age was imputed based on its logarithm to maintain positive values, and its antilogarithm was then used to transform it into a categorical variable. We used this approach to build a multilevel fixed-effect multivariate Poisson regression model for each of our 50 complete datasets. Thus, we obtain adjusted incidence density ratios (IDR) for death for each category of every variable, to assess the magnitude of associations with cyclist death rates. IDR is a good estimate of the relative risk of death across categories of independent variables when, as in this analysis, the risk of death yields exactly the same value as the death rate for a fixed amount of persons-time (ie, the number of cyclists involved in road crashes multiplied by the same follow-up period for all of them). For each IDR, its corresponding 95\% CI was also calculated. We then used the community-contributed 'mim' command for Stata ${ }^{35}$ to combine the estimates obtained for each imputed file according to the Rubin method. ${ }^{36}$

All analyses were done with Stata software (V. 14). ${ }^{37}$

\section{RESULTS}

Tables 1 and 2 summarise descriptive information on cyclist and crash/environment related characteristics. Fatality was a rare event $(2.49 \%)$. The male-to-female ratio was almost 8:1. The main mechanism for crashes was collision with another vehicle $(69.40 \%)$, and most crashes occurred in urban areas $(60.71 \%)$, followed by highways $(35.71 \%)$ and community roads $(3.58 \%)$. Although most crashes occurred during the day $(83.44 \%$ between 9:00 and just before 21:00), many of them (47.48\%) occurred shortly after the end of the morning and afternoon work shifts, that is, from 12:00 to just before 15:00, and from 18:00 to just before 21:00.

Table 3 shows the IDR for the association between cyclist characteristics and the risk of death. A tendency towards a direct association between cyclists' age and death was observed from the third decade of life; the association was statistically significant $(\mathrm{p}<0.05)$ in categories from 35 to 39 years and older, and was greatest in the 'over 74 years' category (IDR 4.61, 95\% CI 3.49 to 6.08 ). Non-use of a helmet was associated with a $43.45 \%$ higher chance 
Table 1 Distribution of cyclist related variables, Spain, 1993-2013

\begin{tabular}{|c|c|c|c|c|c|}
\hline Variable & Category & $\mathbf{N}$ & $\%$ Total & $\mathbf{N}$ & $\begin{array}{l}\% \text { Excluding } \\
\text { missing values }\end{array}$ \\
\hline \multirow[t]{4}{*}{ Death } & Yes & 1643 & 2.49 & 1643 & 2.54 \\
\hline & No & 62969 & 95.44 & 62969 & 97.46 \\
\hline & Unknown & 1365 & 2.07 & - & - \\
\hline & Total & 65977 & 100 & 64612 & 100 \\
\hline \multirow[t]{4}{*}{ Sex } & Male & 55901 & 84.73 & 55901 & 87.13 \\
\hline & Female & 8259 & 12.52 & 8259 & 12.87 \\
\hline & Unknown & 1817 & 2.75 & - & - \\
\hline & Total & 65977 & 100 & 64160 & 100 \\
\hline \multirow[t]{17}{*}{ Age (years) } & $<10$ & 1596 & 2.42 & 1596 & 2.60 \\
\hline & $10-14$ & 6073 & 9.20 & 6073 & 9.89 \\
\hline & $15-19$ & 9065 & 13.74 & 9065 & 14.76 \\
\hline & $20-24$ & 6130 & 9.29 & 6130 & 9.98 \\
\hline & $25-29$ & 5963 & 9.04 & 5963 & 9.71 \\
\hline & $30-34$ & 5797 & 8.79 & 5797 & 9.44 \\
\hline & 35-39 & 5244 & 7.95 & 5244 & 8.54 \\
\hline & $40-44$ & 4632 & 7.02 & 4632 & 7.54 \\
\hline & $45-49$ & 4119 & 6.24 & 4119 & 6.71 \\
\hline & $50-54$ & 3357 & 5.09 & 3357 & 5.46 \\
\hline & $55-59$ & 2555 & 3.87 & 2555 & 4.16 \\
\hline & $60-64$ & 2256 & 3.42 & 2256 & 3.67 \\
\hline & $65-69$ & 1804 & 2.73 & 1804 & 2.94 \\
\hline & $70-74$ & 1361 & 2.06 & 1361 & 2.22 \\
\hline & $>74$ & 1477 & 2.24 & 1477 & 2.40 \\
\hline & Unknown & 4548 & 6.89 & - & - \\
\hline & Total & 65977 & 100 & 61429 & 100 \\
\hline \multirow[t]{4}{*}{ Helmet use } & Yes & 17183 & 26.04 & 17183 & 35.38 \\
\hline & No & 31378 & 47.56 & 31378 & 64.62 \\
\hline & Unknown & 17416 & 26.40 & - & - \\
\hline & Total & 65977 & 100 & 48561 & 100 \\
\hline \multirow{4}{*}{$\begin{array}{l}\text { Psychophysical } \\
\text { circumstances }\end{array}$} & Normal & 53622 & 81.27 & 53622 & 98.32 \\
\hline & Altered ${ }^{\star}$ & 915 & 1.39 & 915 & 1.68 \\
\hline & Unknown & 11440 & 17.34 & - & - \\
\hline & Total & 65977 & 100 & 54537 & 100 \\
\hline \multirow[t]{4}{*}{ Nationality } & Spanish & 57208 & 86.71 & 57208 & 91.69 \\
\hline & Other nationality $\dagger$ & 5184 & 7.86 & 5184 & 8.31 \\
\hline & Unknown & 3585 & 5.43 & - & - \\
\hline & Total & 65977 & 100 & 62392 & 100 \\
\hline \multirow{7}{*}{$\begin{array}{l}\text { Commission of } \\
\text { infraction }\end{array}$} & None & 34607 & 52.45 & 34607 & 52.45 \\
\hline & Distraction & 6851 & 10.38 & 6851 & 10.38 \\
\hline & Incorrect use of lighting & 296 & 0.45 & 296 & 0.45 \\
\hline & Wrong way & 1335 & 2.02 & 1335 & 2.02 \\
\hline & Invading the opposite lane & 1200 & 1.82 & 1200 & 1.82 \\
\hline & Incorrect turning & 1879 & 2.85 & 1879 & 2.85 \\
\hline & Illegal passing & 489 & 0.74 & 489 & 0.74 \\
\hline
\end{tabular}




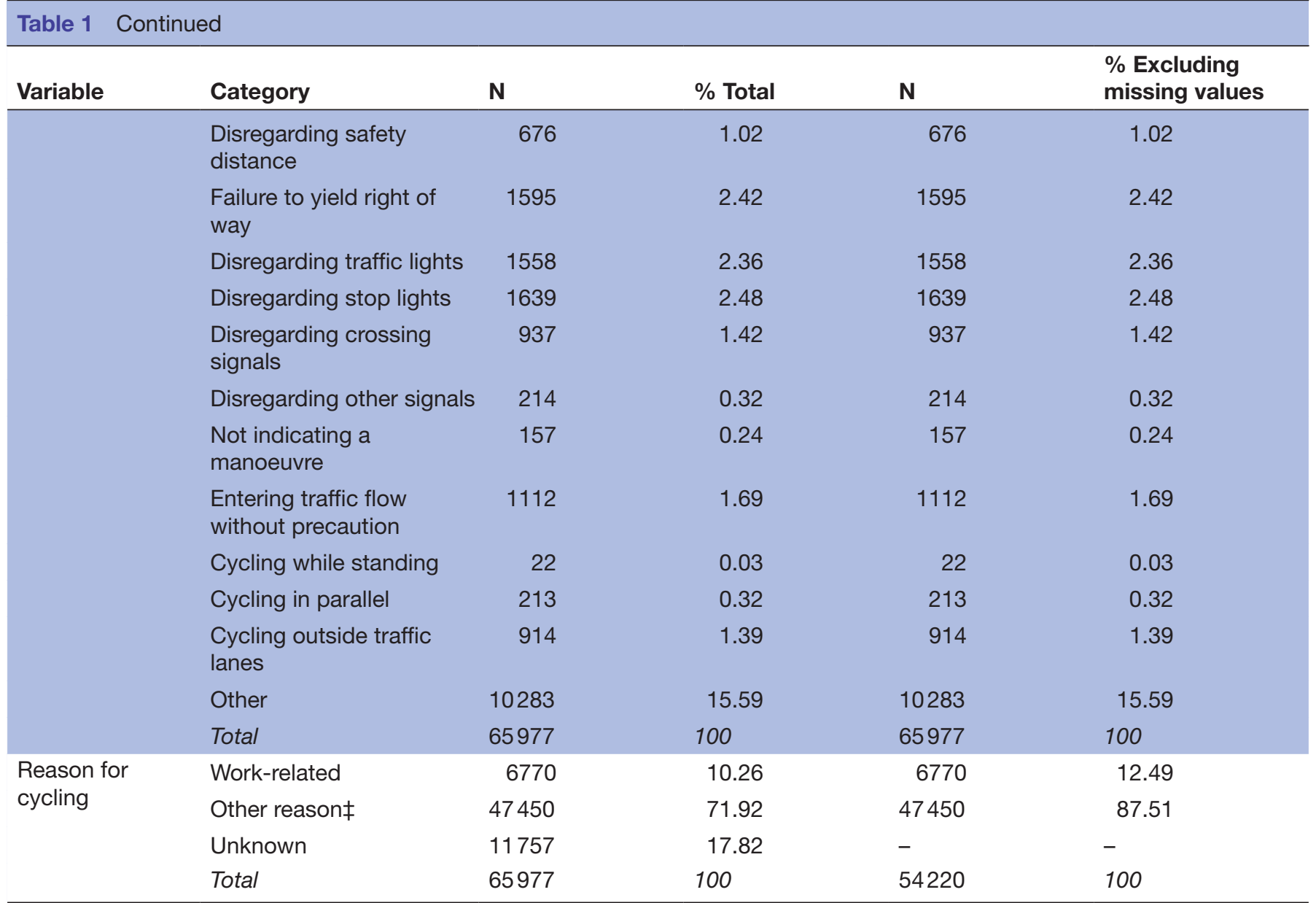

*Including alcohol consumption with breath test, alcohol consumption without breath test, drug consumption, sudden illness, sleepiness or drowsiness, tiredness, or appearing worried, as perceived by the police officer.

†Including French, Moroccan, German, British, Italian, Swiss, Belgian, Dutch, American, other Magreb countries and other countries. fIncluding leaving for or returning from vacation, leaving for or returning from a holiday or long weekend, emergency and leisure.

of death (IDR $1.43,95 \%$ CI 1.25 to 1.64 ). Male gender, psychophysical circumstances and nationality other than Spanish showed a direct association with death. Many recorded cyclist infractions were directly associated with death, with IDR higher than 2 for infractions such as disregarding stop lights or other signals, cycling while standing, illegal passing, invading the opposite lane and cycling outside traffic lanes. However, 'Disregarding safety distance' and 'distraction' were inversely associated with death, but this association was statistically significant only for the latter $(\mathrm{p}<0.05)$. The association for work-related cycling did not differ compared with other motives for cycling (ie, for leisure or for other reasons).

Table 4 shows the IDR for the association between environmental characteristics and the risk of death. There were no conclusive trends according to the type of crash (IDR $0.89,95 \%$ CI 0.78 to 1.00 ), but cycling through an intersection (IDR 1.65 for 'other', 95\% CI 1.46-1.87), in urban areas and on community roads were inversely associated with death. This association was also found when the road surface was altered. However, for adverse meteorological conditions, the association was direct. A direct association with death was also found after midnight, in the category '03:00-05:59' (IDR 1.58, 95\% CI 1.03 to 2.41), whereas an inverse association was found during the day, with a peak at midday between 12:00 and 14:59 (IDR $0.40,95 \%$ CI 0.29 to 0.56 ). Over the 10 -year period analysed here, there was a trend towards a higher likelihood of death in the earlier years.

\section{DISCUSSION}

Our results are generally in agreement with those of previous studies regarding the direction and magnitude of the associations between cyclist and environment related factors and the severity of crashes involving cyclists. ${ }^{7-18}$ Perhaps, our most important finding is the association between non-use of a helmet and a higher chance of death. Although the protective effect of helmet use on the risk of head trauma is widely accepted, ${ }^{8-11} 13-16$ its association with injury severity has been addressed mostly for non-fatal injuries given that relatively few studies to date have focused on its association with death. ${ }^{19} 20$ Although our study is observational and causality cannot 
Table 2 Distribution of crash and environment related variables, Spain, 1993-2013

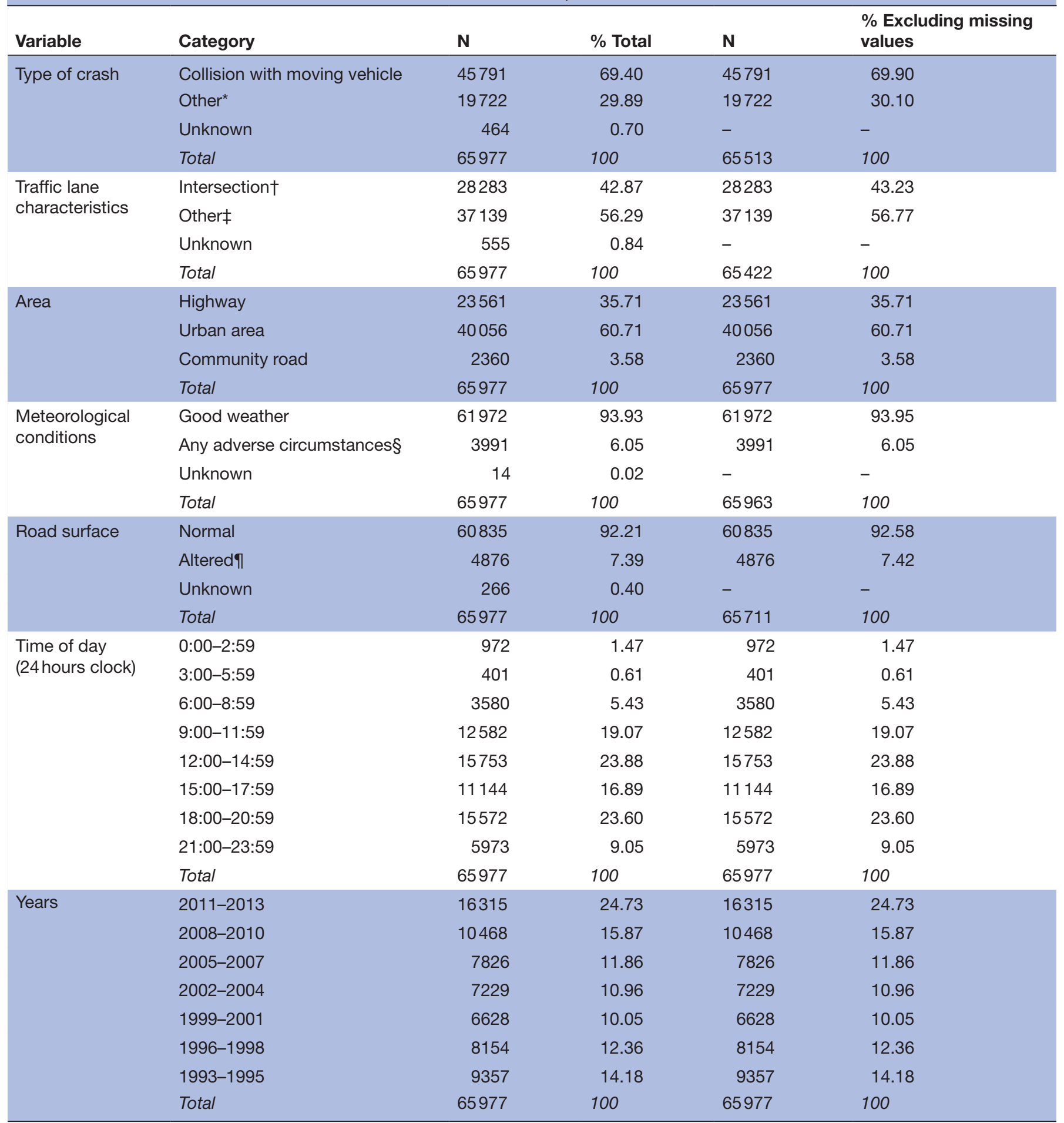

*Including collision with an obstacle (eg, stopped vehicles, pedestrians or animals), overturning, running off the road or other types of crash.

†Including $\mathrm{T}$ or $\mathrm{Y}$ configuration, $\mathrm{X}$ or + configuration, entrance ramp, exit ramp, traffic circle, or other intersections.

łIncluding straightaway, gentle curve, unmarked sharp curve, marked sharp curve without posted speed limit, marked sharp curve with posted speed limit or others.

§Including heavy fog, light fog, light rain, heavy rain, hail, snow, strong winds or other adverse meteorological conditions.

IIncluding shaded, wet, ice, snow, slick formed from water +dirt + oil, loose gravel, oil, or other altered surfaces.

be demonstrated, it is unlikely that residual confounding could entirely explain an association of the magnitude we observed. We are confident that our approach to the analysis was robust given that it included appropriate management of missing values, controlling for betweenprovince-level variance and multivariate adjustment 
Table 3 Adjusted IDR for the association between cyclist related variables and the risk of death in the first 24 hours after a road crash, Spain, 1993-2013

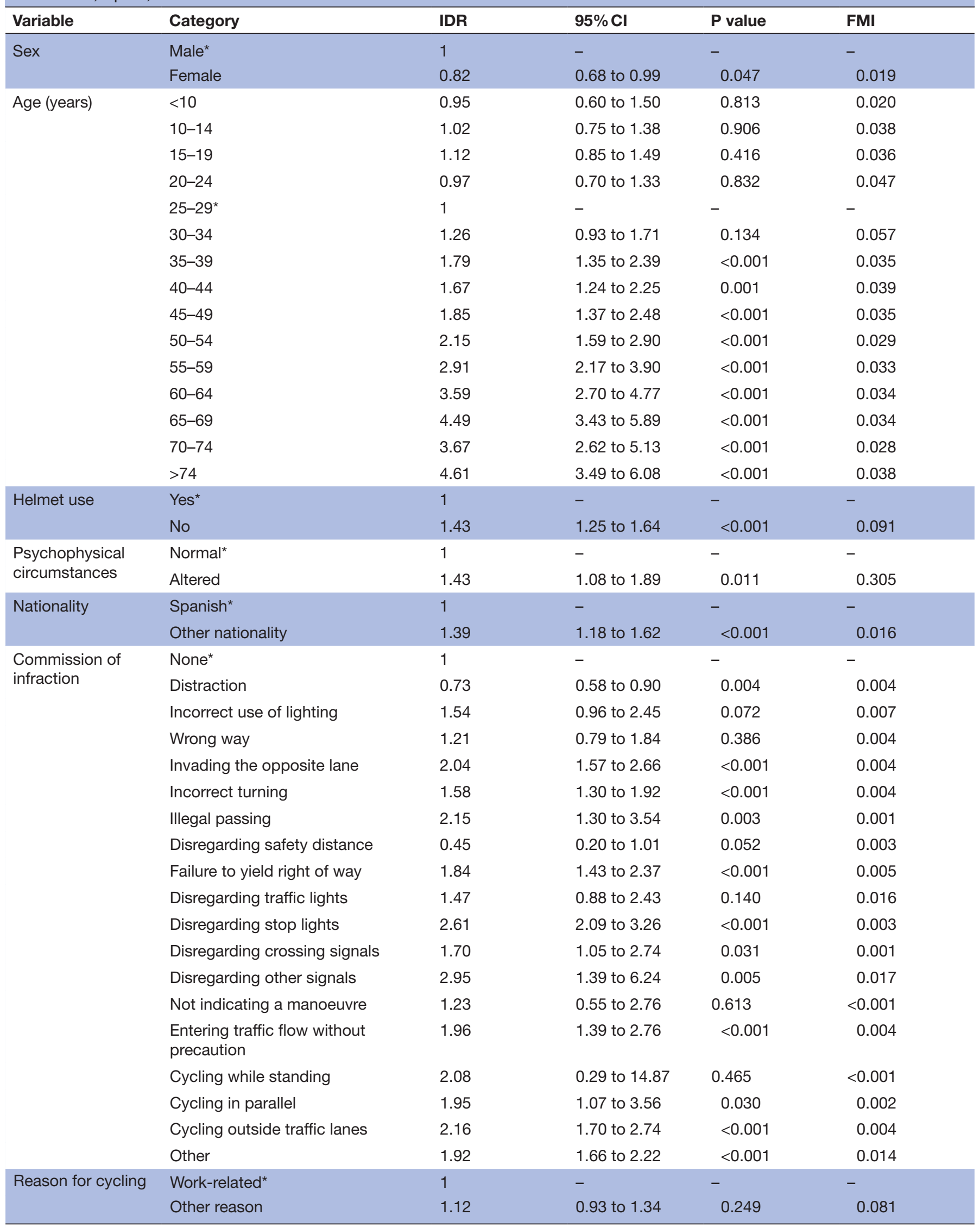

${ }^{*}$ Reference category.

FMI, fraction of missing information; IDR, incidence density ratio. 
Table 4 Adjusted IDR for the association between crash and environment related variables and the risk of death in the first 24 hours after a road crash, Spain, 1993-2013

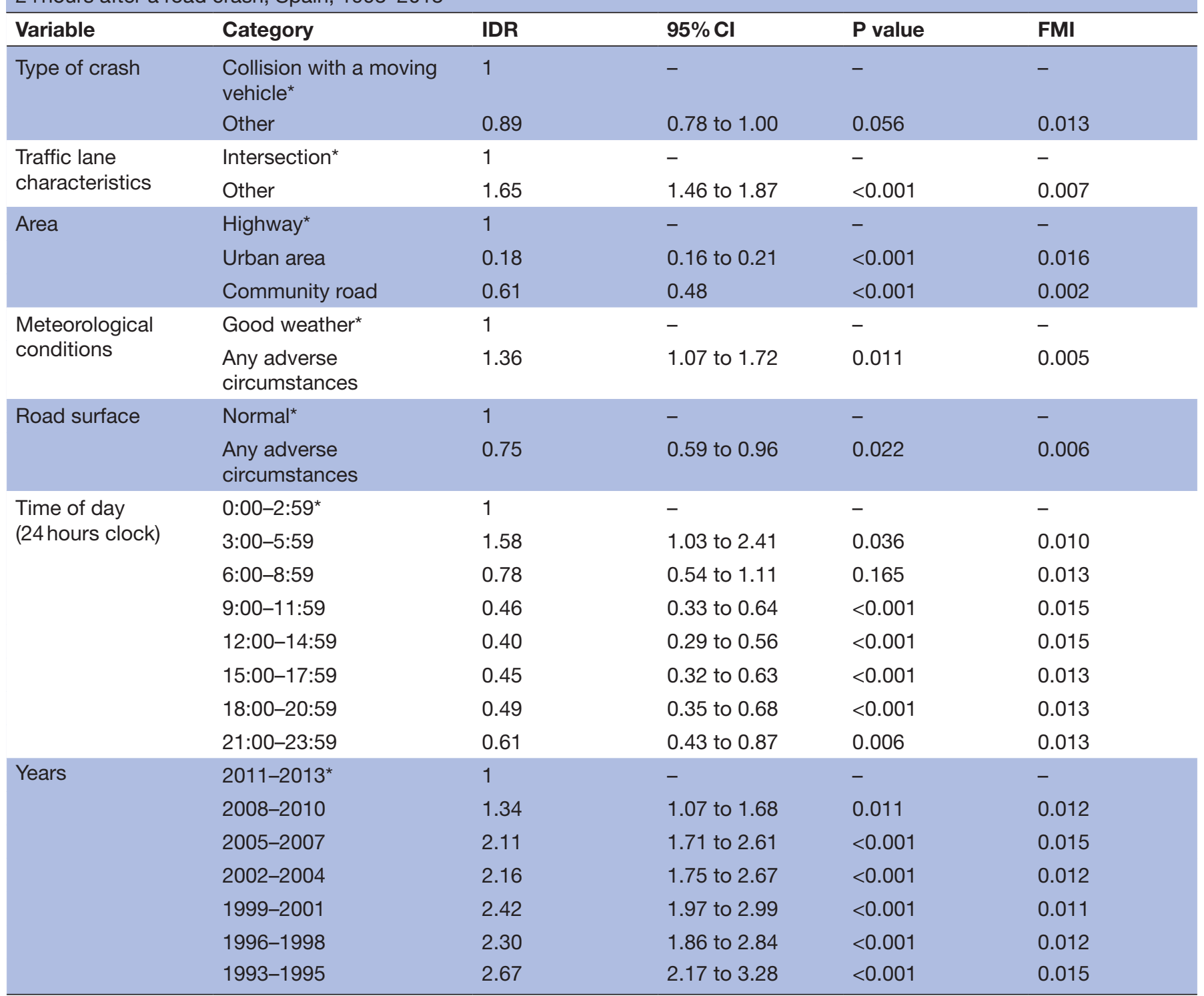

${ }^{*}$ Reference category.

FMI, fraction of missing information; IDR, incidence density ratio.

for the most well-known confounders of the association between helmet use and death. Therefore, taking into account that helmet use is the most easily modifiable cyclist-dependent risk factor, our results suggest that a non-negligible amount of cyclist deaths might be prevented by increasing helmet use in our population of cyclists.

Regarding other cyclist-related variables, the association we found between age and risk of death is consistent with previous studies. ${ }^{81011}$ This association may be explained on the basis of mechanisms such as greater fragility, loss of physical agility, decreased visual acuity and concomitant diseases. ${ }^{38}$ In contrast to other authors, ${ }^{9} 1418$ we found no association between younger age and death.

In relation to gender, we found that the risk of death was higher for males, as reported previously. ${ }^{16}$ This association has been explained as a result of either physical differences or safer behaviours in females, ${ }^{23}$ which may be associated with the severity of the crash itself. Other explanations have been based on the presumably riskier behaviour in males when failing to stop for red lights ${ }^{39}$ and when their risk perception is lower. ${ }^{21}$ On the other hand, female gender has been associated with higher rates of reporting road crashes. ${ }^{40}$ Because we considered only injured cyclists or death as our main outcomes, and assuming there was no difference between genders in deaths recorded in our database, differences in reporting non-fatal road crashes could lead to overestimation of the association with death (if any) in the underreported category. In fact, some authors did not observe this association, ${ }^{8}$ or found female gender to be related with injury severity. ${ }^{12}$ 
According to some authors, alcohol consumption is associated with risky behaviours ${ }^{24} 25$ when cycling and driving other types of vehicles, and is directly associated with injury severity. ${ }^{10} 121417$ This condition could not be investigated in our study because of the dichotomisation process used to account for missing values. The low number of cyclists in the original categories for the 'psychophysical circumstances' variable forced us to combine alcohol consumption, drug consumption, tiredness, sleepiness and other psychophysical circumstances into a single 'altered' category, obscuring the true association between each type of psychophysical circumstance and death. Nevertheless, alcohol consumption with and without a breath test was the most prevalent condition included in the 'altered' category, and showed a direct association with death. However, this association should be viewed with caution because of potential shortcomings in the validity of our data source.

Non-Spanish nationality also showed a stronger association with death, but this should likewise be interpreted with care. We could not obtain information about cyclists' expertise, and for non-Spanish cyclists, we did not know how long they had been living in Spain, or whether they had changed their cycling patterns while living abroad. Furthermore, all non-Spanish cyclists were clustered in a single subgroup which included people from countries which may differ widely in a large variety of aspects such as social and cultural characteristics as well as cycling infrastructure in their country of origin. This subgroup was thus too heterogeneous for informative comparisons. Consequently, the association found in our study undoubtedly deserves further research designed to address its underlying factors.

Like Kim and colleagues, ${ }^{10}$ we observed that most traffic infractions (11 out of 18) were directly associated with death. Distraction while walking or driving has been deeply explored, but it is not the case while bicycling. ${ }^{41}$ There are inherent limitations to record distractions when the cyclist died at the crash scene. In our study, 'Distraction' was unexpectedly the only infraction inversely associated with death and statistically significant, but this category included a wide range of sources of distraction, such as involuntary risky behaviours and intentionally committed behaviours (eg, use of technological devices). Although other authors have found distraction to be associated with a higher risk of crash, ${ }^{22}$ to our knowledge, the association between distractions and the severity of the crash has not been previously assessed. A possible explanation for this inverse association with death could be the lower speed (an unobserved variable) while cycling distracted. ${ }^{41}$ In relation with the reason for cycling, we found no associations with the likelihood of death. However, previous studies showed that work-related or utilitarian cycling was associated with less severe injuries because of cyclists' expertise, choice of safer routes and helmet use, ${ }^{13}$ although greater injury severity was also associated with more experience and more frequent cycling. ${ }^{12}$ Although some authors have reported different injury severity depending on the type of crash, especially when a motor vehicle was involved, ${ }^{12} 131642$ in the present study, the direct association between death and collisions with moving vehicles did not differ significantly in comparison to other types of crashes (IDR 0.89 , $95 \%$ CI 0.78 to 1.00 ). Nevertheless, because type of crash was a binary variable in our analysis (see Statistical analysis section), all other types of collisions with moving vehicles were included in a single category and compared with other types of crashes (such as collisions with an obstacle, overturning or running off the road), hence the two groups were heterogeneous. Furthermore, unless the cyclist is fatally injured, cyclists are probably more likely to receive police assistance when they collide with another vehicle. Therefore, cyclists who sustained minor injuries in the 'other crashes' category were likely to be underrepresented in our sample.

Regarding environment-related variables, although some authors found no clear association with traffic lane characteristics or road geometry, ${ }^{11}{ }^{12}$ we identified an inverse association between intersections and death compared with other road configurations (straight roads or curves), in accordance with previous findings for injury severity. ${ }^{14}$ But again, our two categories were heterogeneous, and the risks may differ among for different types of intersection. ${ }^{9}{ }^{43}$

The location of the crash showed a close relationship with fatalities. Previous studies have reported less severe injuries in dense urban settings, and more severe injuries on rural or community roads. We found an inverse association with death for crashes in urban areas and community roads compared with highways. This association is probably related to the higher speeds reached on highways by cyclists or the other vehicles involved in crashes. In fact, speed has been previously associated with injury severity. ${ }^{1011} 131416$

Adverse meteorological conditions were directly associated with death, as reported by other authors. ${ }^{9}{ }^{10}$ This association is probably due to lower cyclist conspicuity under adverse weather conditions, although other authors found no clear association. ${ }^{712} 13$ On the other hand, altered road surfaces were inversely associated with risk of death, which may be the result of cycling or driving at lower speeds. Nevertheless, other authors have reported more severe injuries on altered surfaces, ${ }^{9} 14$ or found no association at all. ${ }^{711}$ More research is needed to characterise the influence of weather and road conditions on risk of death among cyclists, given the discrepancies among findings from different studies.

Although the frequency of crashes was much greater during daylight hours, there was a direct association between crashes that occurred at night and death, as also found by Boufous $e t a l^{11}$ and Wang $e t a l,{ }^{9}$ with a peak in the early morning hours, as reported by Asgarzadeh et $a l^{7}$ Other authors, however, found no association between time of the crash and injury severity or death, although one Danish study reported an association with daylight hours, probably because of the high standard of 
nighttime roadway lighting in Denmark. ${ }^{14}$ Apart from the lack of conspicuity, ${ }^{44}$ factors such as alcohol consumption, speed and exhaustion may play major roles in this association. ${ }^{74}$ Finally, the lower risk of death in crashes recorded in more recent years in Spain may be explained by improvements in cycling infrastructure,${ }^{46}$ improved healthcare for injured cyclists ${ }^{1}$ and increased reporting of less serious road crashes by the police.

\section{Strengths and limitations}

Our data source for this analysis was the Spanish National Registry of Road Crashes with Victims. This registry contains information recorded over many years by police officers on a standard form. Our large sample size and total number of cyclist deaths made it possible for us to precisely estimate the magnitude of the associations between each variable in the model and fatal injuries. Our choice of main outcome categories reduced the possible effect of misrepresentation for certain independent variables in this police-based registry. Furthermore, the statistical approach used here considered variability in the outcome variable across provinces in Spain, and was intended to decrease the effect of missing values that could be explained by the remaining variables.

Nevertheless, a main limitation of our study is its observational nature, which prevents us from suggesting causal interpretations for the associations we found. Given that our analysis is based on information from a police-based registry designed to collect information on all types of road traffic crashes, as noted in the Methods section, selection bias is an important issue given the assumption that less serious crashes were underrepresented, because of a direct association between injury severity and reporting rates to the police. ${ }^{47-49}$ Behavioural differences and differences in representation rates related to the categories for specific variables (eg, gender) could not be measured with the available data, and this may have led to overestimation or underestimation of some of the observed associations. Regarding helmet use, we do not have information on the characteristics of the helmets, and cannot confirm that they were being worn correctly at the moment of the crash. Although we used a multiple imputation procedure to compensate for missing information, this method only partially resolves issues related with missing data; therefore, our results may still be affected by biases of an undetermined magnitude. Furthermore, the dichotomisation used for our multiple imputation procedure forced us to combine heterogeneous categories for some of the variables (eg, psychophysical circumstances), so the results for these variables should be considered with due caution. Bias is also a potential limitation, because of the subjective nature of some variables recorded by police officers at the crash scene.

Finally, the lack of information regarding vehicle speed is an important limitation in our study. Although this is probably the most important factor affecting the severity of cyclists' injuries, no direct information was available for vehicle speed when the crash occurred.

\section{CONCLUSIONS}

We found strong associations between several cyclist and environment related variables and the probability of death, and suggest that these associations should be taken into account in efforts to prioritise public health measures aimed at reducing the number of cycling-related fatalities. In particular, we believe helmet use by cyclists needs to be encouraged. Although we are aware that the magnitude of the association between non-helmet use and death is not entirely causal, it supports the hypothesis that helmet use may significantly reduce the risk of death among cyclists involved in road crashes. Although using a helmet is now mandatory for all cyclists on open roads in Spain, our data show that even in recent years, the proportion of non-helmet use has been non-negligible. Another topic that deserves attention is the risk in older cyclists, considering that this subgroup of cyclists will very likely grow in the coming years. Finally, the reasons for the higher risk of death during nighttime cycling merit further investigation in order to manage factors that are potentially modifiable by, for example, encouraging measures to improve cyclist conspicuity.

\section{Author affiliations}

${ }^{1}$ Department of Preventive Medicine and Public Health, School of Medicine, University of Granada, Granada, Spain

${ }^{2}$ Doctoral Program in Clinical Medicine and Public Health, University of Granada, Granada, Spain

${ }^{3}$ Centros de Investigación Biomédica en Red de Epidemiología y Salud Pública (CIBERESP), Barcelona, Spain

${ }^{4}$ Instituto de Investigación Biosanitaria de Granada (ibs.GRANADA), Granada, Spain ${ }^{5}$ Escuela Nacional de Sanidad, Instituto de Salud Carlos III, Madrid, Spain ${ }^{6}$ Department of Public Health \& Maternal and Child Health, Complutense University of Madrid, Madrid, Spain

Acknowledgements We wish to thank the Spanish General Directorate of Traffic (DGT) for allowing access to their database of Road Crashes with Victims, CIBERESP and ibs.GRANADA for their help and K. Shashok for improving the English usage in the manuscript.

Contributors All authors meet the conditions for authorship. PLC conceived and designed the study, helped to draft the manuscript and critically revised it. DMS and VMR carried out the literature review and prepared the first draft of the manuscript. JPM, EMR and LMMR helped with the literature review and critically reviewed the manuscript. EJM critically reviewed the first draft of the manuscript, proposed corrections and provided methodological advice. All authors approved the final version of this manuscript. The present article is part of the doctoral thesis of Daniel Molina-Soberanes in the Clinical Medicine and Public Health program at the University of Granada.

Funding This work was partially supported by the National Council of Science and Technology of Mexico [doctorate grant number 410668].

Competing interests None declared.

Patient consent for publication Not required.

Provenance and peer review Not commissioned; externally peer reviewed.

Data availability statement All data relevant to the study are included in the article or uploaded as supplementary information.

Open access This is an open access article distributed in accordance with the Creative Commons Attribution Non Commercial (CC BY-NC 4.0) license, which permits others to distribute, remix, adapt, build upon this work non-commercially, and license their derivative works on different terms, provided the original work is properly cited, appropriate credit is given, any changes made indicated, and the use is non-commercial. See: http:// creativecommons.org/licenses/by-nc/4.0/. 


\section{REFERENCES}

1. World Health Organization (WHO). Global status report on road safety 2015, 2015.

2. Johan de Hartog J, Boogaard H, Nijland H, et al. Do the health benefits of cycling outweigh the risks? Environ Health Perspect 2010;118:1109-16.

3. Rifaat SM, Tay R, de Barros A. Effect of street pattern on the severity of crashes involving vulnerable road users. Accid Anal Prev 2011:43:276-83.

4. GESOP, Gabinet d'Estudis Socials i Opinió Pública SL. Barómetro de la Bicicleta en España. Informe de Resultados, 2015. Available: http://www.ciudadesporlabicicleta.org/web/wp-content/uploads/ Barómetro de la Bicicleta en España 2015 - Red de Ciudades por la Bicicleta.pdf

5. Dirección General de Tráfico. Las principales cifras de la Siniestralidad vial España 2015, 2016. Available: http://www.dgt.es/ Galerias/seguridad-vial/estadisticas-e-indicadores/publicaciones/ principales-cifras-siniestralidad/Las-principales-cifras-2016.pdf

6. Dirección General de Tráfico. Las principales cifras de la Siniestralidad vial España 2017, 2018. Available: http://www.dgt.es/Galerias/ seguridad-vial/estadisticas-e-indicadores/publicaciones/principalescifras-siniestralidad/Las-principales-cifras-2017-Internet.pdf

7. Asgarzadeh M, Fischer D, Verma SK, et al. The impact of weather, road surface, time-of-day, and light conditions on severity of bicyclemotor vehicle crash injuries. Am J Ind Med 2018;61:556-65.

8. Bambach MR, Mitchell RJ, Grzebieta RH, et al. The effectiveness of helmets in bicycle collisions with motor vehicles: a case-control study. Accid Anal Prev 2013;53:78-88.

9. Wang C, Lu L, Lu J. Statistical analysis of bicyclists' injury severity at unsignalized intersections. Traffic Inj Prev 2015;16:507-12.

10. Kim J-K, Kim S, Ulfarsson GF, et al. Bicyclist injury severities in bicycle-motor vehicle accidents. Accid Anal Prev 2007;39:238-51.

11. Boufous $S$, de Rome $L$, Senserrick T, et al. Risk factors for severe injury in cyclists involved in traffic crashes in Victoria, Australia. Accid Anal Prev 2012;49:404-9.

12. Cripton PA, Shen H, Brubacher JR, et al. Severity of urban cycling injuries and the relationship with personal, trip, route and crash characteristics: analyses using four severity metrics. BMJ Open 2015;5:e006654.

13. Hagel BE, Romanow NTR, Enns N, et al. Severe bicycling injury risk factors in children and adolescents: a case-control study. Accid Anal Prev 2015;78:165-72.

14. Kaplan S, Vavatsoulas K, Prato CG. Aggravating and mitigating factors associated with cyclist injury severity in Denmark. J Safety Res 2014;50:75-82.

15. Persaud N, Coleman E, Zwolakowski D, et al. Nonuse of bicycle helmets and risk of fatal head injury: a proportional mortality, casecontrol study. Can Med Assoc J 2012;184:E921-3.

16. Rivara FP, Thompson DC, Thompson RS. Epidemiology of bicycle injuries and risk factors for serious injury. Inj Prev 1997;3:110-4.

17. Sethi M, Heyer JH, Wall S, et al. Alcohol use by urban bicyclists is associated with more severe injury, greater Hospital resource use, and higher mortality. Alcohol 2016;53:1-7.

18. Vanlaar W, Mainegra Hing M, Brown S, et al. Fatal and serious injuries related to vulnerable road users in Canada. J Safety Res 2016;58:67-77

19. Olivier J, Creighton P. Bicycle injuries and helmet use: a systematic review and meta-analysis. Int J Epidemiol 2017;46:dyw360-92.

20. Høye A. Bicycle helmets - To wear or not to wear? A meta-analyses of the effects of bicycle helmets on injuries. Accid Anal Prev 2018;117:85-97.

21. Useche SA, Montoro L, Alonso F, et al. Does gender really matter? A structural equation model to explain risky and positive cycling behaviors. Accid Anal Prev 2018;118:86-95.

22. Useche SA, Alonso F, Montoro L, et al. Distraction of cyclists: how does it influence their risky behaviors and traffic crashes? PeerJ 2018;6:e5616.

23. Emond CR, Tang W, Handy SL. Explaining gender difference in Bicycling behavior. Transp Res Rec 2009;2125:16-25.

24. Crocker P, Zad O, Milling T, et al. Alcohol, bicycling, and head and brain injury: a study of impaired cyclists' riding patterns R1. Am J Emerg Med 2010;28:68-72.

25. Orsi C, Ferraro OE, Montomoli C, et al. Alcohol consumption, helmet use and head trauma in cycling collisions in Germany. Accid Anal Prev 2014;65:97-104.
26. Peng $\mathrm{Y}$, Chen $\mathrm{Y}$, Yang J, et al. A study of pedestrian and bicyclist exposure to head injury in passenger CAR collisions based on accident data and simulations. Saf Sci 2012;50:1749-59.

27. Rojas-Rueda D, de Nazelle A, Tainio M, et al. The health risks and benefits of cycling in urban environments compared with CAR use: health impact assessment study. BMJ 2011;343:d4521.

28. Rojas-Rueda D, de Nazelle A, Teixidó O, et al. Health impact assessment of increasing public transport and cycling use in Barcelona: a morbidity and burden of disease approach. Prev Med 2013:57:573-9.

29. Useche SA, Alonso F, Montoro L, et al. When age means safety: data to assess trends and differences on rule knowledge, risk perception, aberrant and positive road behaviors, and traffic crashes of cyclists. Data Brief 2019;22:627-34.

30. Alonso F, Esteban $\mathrm{C}$, Useche $\mathrm{S}$, et al. Effect of road safety education on road risky behaviors of Spanish children and adolescents: findings from a national study. Int $J$ Environ Res Public Health 2018;15:2828.

31. Martínez-Ruiz V, Jiménez-Mejías E, Amezcua-Prieto C, et al. Contribution of exposure, risk of crash and fatality to explain ageand sex-related differences in traffic-related cyclist mortality rates. Accid Anal Prev 2015;76:152-8.

32. 32 Boletín Oficial del Estado, num 289 2014. Orden INT/2223/2014, de 27 de octubre, POR La que Se regula La comunicación de la información al Registro Nacional de Víctimas de Accidentes de Tráfico. Available: https://www.boe.es/boe/dias/2014/11/29/pdfs/ BOE-A-2014-12411.pdf

33. van Buuren S. Multiple imputation of discrete and continuous data by fully conditional specification. Stat Methods Med Res 2007;16:219-42.

34. Royston P. Multiple imputation of missing values: further update of ice, with an emphasis on categorical variables. Stata $J$ 2009;9:466-77.

35. Royston P, Carlin JB, White IR. Multiple imputation of missing values: new features for MIM. Stata J 2009;9:252-64.

36. KH L, Raghunathan TE, Rubin DB. Large-Sample significance levels from multiply Imputed data using Moment-Based statistics and an $\mathrm{F}$ reference distribution. J Am Stat Assoc 1991;86:1065-73.

37. StataCorp. Stata statistical software: release 14 SE. Release 14, 2015.

38. Anstey KJ, Wood J, Lord S, et al. Cognitive, sensory and physical factors enabling driving safety in older adults. Clin Psychol Rev 2005;25:45-65.

39. Pai C-W, Jou R-C. Cyclists' red-light running behaviours: An examination of risk-taking, opportunistic, and law-obeying behaviours. Accident Analysis \& Prevention 2014:62:191-8.

40. Loo BPY, Tsui KL. Factors affecting the likelihood of reporting road crashes resulting in medical treatment to the police. Inj Prev 2007;13:186-9.

41. Stavrinos D, Pope CN, Shen J, et al. Distracted walking, Bicycling, and driving: systematic review and meta-analysis of mobile technology and youth crash risk. Child Dev 2018;89:118-28.

42. O'Hern S, Oxley J. Fatal cyclist crashes in Australia. Traffic Inj Prev 2018;19:S27-31.

43. Harris MA, Reynolds CCO, Winters M, et al. Comparing the effects of infrastructure on bicycling injury at intersections and non-intersections using a case-crossover design. Inj Prev 2013;19:303-10.

44. Thornley SJ, Woodward A, Langley JD, et al. Conspicuity and bicycle crashes: preliminary findings of the Taupo bicycle study. Injury Prevention 2008:14:11-18.

45. de Waard D, Houwing S, Lewis-Evans B, et al. Bicycling under the influence of alcohol. Transp Res Part F Traffic Psychol Behav 2016;41:302-8.

46. Reynolds CCO, Harris MA, Teschke K, et al. The impact of transportation infrastructure on bicycling injuries and crashes: a review of the literature. Environ Health 2009;8.

47. Elvik R, Mysen A. Incomplete accident reporting: meta-analysis of studies made in 13 countries. Transp Res Rec 1999;1665:133-40.

48. Langley JDet al. Missing cyclists. Injury Prevention 2003:9:376-9.

49. Shinar D, Valero-Mora P, van Strijp-Houtenbos M, et al. UnderReporting bicycle accidents to police in the cost TU1101 international survey: Cross-country comparisons and associated factors. Accid Anal Prev 2018;110:177-86. 